\title{
Genetically attenuated Trypanosoma cruzi parasites as a potential vaccination tool
}

Cecilia Pérez Brandan* and Miguel Ángel Basombrío

Instituto de Patología Experimental-CONICET; Universidad Nacional de Salta; Salta, Argentina

Key words: Trypanosoma cruzi, gene knockout, dhfr-ts, chagas disease

Submitted: 03/30/12

Revised: 05/04/12

Accepted: 05/08/12

http://dx.doi.org/

*Correspondence to: Cecilia Pérez Brandan; Email: cecilia.perezbrandan@conicet.gov.ar dhfr-ts gene in Trypanosoma cruzi generates attenuated parasites able to confer protection against a virulent challenge. PLoS Negl Trop Dis 2011; 5:1418; PMID:22180798; http://dx.doi. org/10.1371/journal.pntd.0001418.
$\mathrm{C}$ hagas disease is the clinical manifestation of the infection produced by the parasite Trypanosoma cruzi. Currently there is no vaccine to prevent this disease and the protection attained with vaccines containing non-replicating parasites is limited. Genetically attenuated trypanosomatid parasites can be obtained by deletion of selected genes. Gene deletion takes advantage of the fact that this parasite can undergo homologous recombination between endogenous and foreign DNA sequences artificially introduced in the cells. This approach facilitated the discovery of several unknown gene functions, as well as allowing us to speculate about the potential for genetically attenuated live organisms as experimental immunogens. Vaccination with live attenuated parasites has been used effectively in mice to reduce parasitemia and histological damage, and in dogs, to prevent vectordelivered infection in the field. However, the use of live parasites as immunogens is controversial due to the risk of reversion to a virulent phenotype. Herein, we present our results from experiments on genetic manipulation of two T. cruzi strains to produce parasites with impaired replication and infectivity, and using the mutation of the $d h f r$-ts gene as a safety device against reversion to virulence.

\section{Introduction}

A century after the discovery of Chagas disease, there is still no effective drug treatment or vaccine to fight this affection. This disease is the clinical manifestation of the infection by the parasite Trypanosoma cruzi. This parasite belongs to the Trypanosomatidae family and is transmitted primarily through insect vectors, through blood transfusion or during pregnancy, producing severe heart and digestive tract disease among poor people in many countries of Latin America. ${ }^{1}$ Development of an effective vaccine is thus urgently needed.

To date, so-called genetic engineering approaches have provided powerful tools for elucidating unknown gene functions and factors involved in gene regulation. Gene targeted replacement by homologous recombination has been one of the most powerful methods not only for modifying and testing gene function, but for creating genetically attenuated organisms. Attenuation of infectivity has been achieved by the deletion of targeted genes, and some engineered protozoan parasites have been successfully tested as live vaccines. For example, Plasmodium parasites are the protozoans which have been genetically modified and evaluated as potential vaccine in a larger extent. ${ }^{2,3}$ Similar advances were accomplished in the trypanosomatid Leishmania $\mathrm{sp}^{4}$ and to a lesser extent, in Trypanosoma cruzi. ${ }^{5-8}$ Herein, we review recent progress in the development of genetically attenuated Trypanosoma cruzi parasites and their evaluation as experimental vaccine candidates. ${ }^{7}$

\section{Generation of Trypanosoma cruzi Lines Carrying a Deletion of the dhfr-ts Gene}

Several human parasites lacking specific genes have been successfully generated, 
including the deletion of the TbALG3 gene in Trypanosoma brucei, or the gene encoding the Oligopeptidase B in Leishmania major and genes involved in Plasmodium cell-infection. ${ }^{9-11}$ In our experience, monoallelic mutants of T. cruzi genes can readily be obtained, but complete biallelic abrogation of a targeted gene is not an easy task. Indeed, few genes have been either partially or completed deleted from the genome of this intriguing parasite., ${ }^{72-25}$

The dhfr-ts gene of trypanosomatids, is a single copy gene which encodes the bifunctional enzyme dihydrofolate reductase-thymidylate synthase (DHFR-TS). ${ }^{26}$ Leishmania major and Trypanosoma brucei parasites completely lacking the $d h f r-$ ts gene were generated by homologous recombination. ${ }^{27,28}$ However, our attempts to obtain T. cruzi null mutants for this gene were not successful. An endogenous $d h f r-t s$ copy was always detected after the procedures, despite the selection marker being in the correct locus replacing the corresponding $d h f r-t s$ allele. Speculating that the problem could be related to the genetic background of the T. cruzi strain used (naturally attenuated TCC strain); we also tested the procedure with well characterized T. cruzi virulent strains, such as CL Brener and Tulahuen, but without success. Alternatively, and as it has been shown for Leishmania, the parasites may undergo duplication events to avoid the loss of an essential gene. ${ }^{29,30}$ Cruz et al. ${ }^{27}$ were able to obtain $d h f r$-ts null mutant parasites from an attenuated Leishmania strain, but not from a virulent one. After transfections and antibiotic selection, these authors detected mainly tetraploid and polyploid parasites, suggesting that in a natural population of Leishmania exists different levels of ploidy, and that those with an increased number of chromosomes get selected. ${ }^{29}$ However, in our studies with $T$. cruzi, irrespective of the phenotype of the strain used in the experiments (virulent or attenuated), at least one copy of the $d h f r-t s$ gene still remains, again suggesting that it is essential for parasite survival. Similarly, locus amplification was the outcome of experiments aimed to obtain null mutant T. cruzi parasites for the enoyl-CoA hydratase (ech) and the UDP-Glcp 49-epimerase (TcGALE) genes. ${ }^{21,25}$ Assessing the frequency at which these amplification/ duplication events take place could help to optimize targeted deletion protocols for probing the plasticity of the genome of this parasite.

\section{Biological Behavior of dhfr-ts monoalelic Mutant Trypanosoma cruzi Parasites}

Previous studies have shown that deletion of the dhfr-ts gene could render trypanosomatid parasites auxotrophic and lead to parasite death. ${ }^{27,28}$ The DHFR-TS enzyme catalyzes sequential reactions in the biosynthesis of thymidine monophosphate (dTMP), which is needed for DNA synthesis and cell replication. Therefore inhibition of this enzyme results in a deficit of thymidine and consequently death. It has been reported that L. major $d h f r-t s^{-/}$parasites are unable to replicate in macrophages in vitro and to cause permanent disease in experimental animals, most likely attributed to the auxotrophism generated in this mutant line. ${ }^{31}$ It has also been shown that DHFR-TS is essential for Trypanosoma brucei, null lines of these parasites are completely unable to grow in vitro, and lack the ability to establish and maintain infections in mice. ${ }^{28}$ Since we were not able to generate null mutations for the parasite in this gene, assays for auxotrophism could not be performed. However, we detected significant impairment in growth of the $d h f r-t s^{+/-}$mutant compared with the wild-type TCC parasites.

The Tulahuen strain of $T$. cruzi is highly virulent, and the deletion of one $d h f r$-ts allele has been proven to produce a remarkable attenuation of its virulence for a variety of experimental animals with different genetic background. The significant loss of the ability of Tulahuen $d h f r$ $t^{+/}$parasites to develop blood parasitism in immunocompetent mice suggests that this gene may be considered as a virulence factor of T. cruzi. In contrast, the wildtype TCC T. cruzi strain was originally attenuated, and infections were detected only with highly sensitive methods applied to very young, immunodeficient or immunosuppressed mice. Moreover, we were not able to recover parasites from infected mice after two months of infection. Introduction of the dhfr-ts mutation led to additional attenuation of this subline, since prior to the parasitological and molecular detection assays, animals were submitted to an immunosuppression regimen. Despite this, no positive PCR or hemoculture were found in the group of animals infected with TCC $d h f r-$ $t^{+/-}$mutant parasites. These results are in agreement with previous data indicating that parasite recovery in low level infections is considerably arduous. TCC $d h f r-$ $t^{+/}$parasites were not detected by sensitive procedures used to confirm parasite clearance by effective drug treatment, ${ }^{32}$ suggesting that these mutant parasites, if not totally eliminated, may be maintained at extremely low numbers.

\section{Use of Genetically Attenuated dhfr-ts $^{\text {t- }}$ Trypanosoma cruzi Parasites as Experimental Vaccines}

As a general rule, the success of liveattenuated microorganisms as vaccines against yellow fever, smallpox, measles, rubella, tuberculosis, etc., suggests that the more similar a vaccine is to the natural disease, the better is the protective immune response. ${ }^{33-35}$ The efficacy of these vaccines depends on the use of live naturally attenuated organisms and a true, albeit self-limited infection is necessary to attain strong and long lasting protection. ${ }^{36}$ On this basis, it would not be unreasonable to think that genetically attenuated intracellular parasites could be tested as experimental vaccines. Furthermore, in Plasmodium and Leishmania, this approach has met major advances. ${ }^{3,4}$ However, in the case of T. cruzi, the evaluation of genetically attenuated parasites as experimental vaccines still deserves further experimentation.

We have evaluated the protective effect of $d h f r-t s^{+/}$TCC parasites and the cellular immune responses in short and long-term immunization schemes. Parasite-specific $\mathrm{CD}^{+} \mathrm{T}$ cells have been shown to be crucial in the immunity against $T$. cruzi. ${ }^{37} \mathrm{We}$ first investigated whether these mutant parasites were able to trigger cellular and humoral immune responses in infected animals comparable to the induced by infection of wild-type TCC parasites. The use of an immunodominant $T$. cruzi peptide encoded in trans-sialidase family genes 
has been utilized successfully to estimate the percentage of $T$. cruzi specific $\mathrm{CD} 8^{+}$ $\mathrm{T}$ cells in experimental infections. ${ }^{38}$ This specific $\mathrm{CD}^{+}{ }^{+} \mathrm{T}$-cell response against a single epitope (TSKb20) was considerably lower in mice infected with TCC $d h f r-t s^{+-}$ parasites than in mice infected with TCC wild type, even when using highly susceptible IFN $\gamma^{-}$background mice. Among several factors, the development of specific $\mathrm{CD}^{+} \mathrm{T}$ cells is not only determined by the variety of available antigens but by the quantity. These results are most likely correlated with the limited infectivity of TCC mutant parasites and therefore with a late or inefficient antigen presentation by dendritic cells. The antibody response of non-infected or infected mice with TCC mutant or wild-type parasites did not differ significantly. Thus, antibody responses do not seem to be mediators of enhanced protective immunity induced by vaccination with TCC attenuated lived parasites.

The naturally attenuated TCC strain of $T$. cruzi has been successfully used by our group not only in vaccination assays involving laboratory mice but in protection field studies in guinea pigs and dogs. ${ }^{39-41}$ TCC inoculations protected these domestic reservoir animals against naturally transmitted infection. Moreover, the trafficking of parasites from hosts to vectors was significantly reduced, the TCC strain acting as a transmission-blocking vaccine. These results were promising for further prophilaxis trials but the risk of reversion to a virulent phenotype could not be excluded, since the basis of attenuation of the TCC strain is not known. The introduction of additional attenuating mutations, targeted to identified virulence genes could thus operate as a safety device and justified further efforts to genetically manipulate the TCC strain and evaluate its protective capacity in experimental animals.

Both the $d h f r-t s^{+/}$mutant and the wildtype TCC parasites generated a similar level of protection against virulent infection, either after short $(15 \mathrm{~d})$ and long $(370$ d) intervals between immunization and challenge (Figs. 1 and 2). In the immunized animals, CD8 ${ }^{+}$T-cells responses were monitored by determining TSKb-20 specific proliferation, 15 and $370 \mathrm{~d}$ after immunization, in parallel comparison of

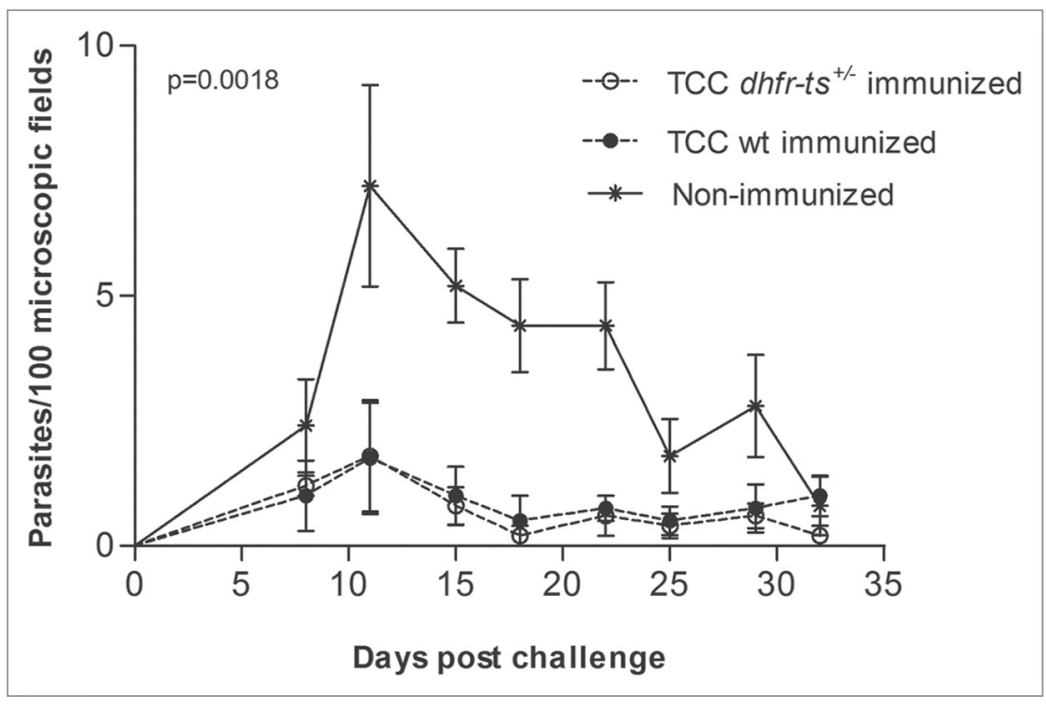

Figure 1. Short-term protection in immunocompetent mice infected with TCC mutant parasites. Parasitemia curve of Balb/c mice infected with TCC $d h f_{r-t s^{+/}}$metacyclic trypomastigotes, TCC wild-type metacyclic trypomastigotes or PBS and challenge with $5 \times 10^{3}$ virulent Tulahuen blood trypomastigotes. Values are given as means; error bars indicate standard errors of the mean (DOI:10.1371/journal.pntd.0001418. g005).

the mutant and the wild type. A significant proliferation was detected after $15 \mathrm{~d}$ in TCC wild-type infected mice which was no longer observed at $360 \mathrm{~d}$ and was not matched by $d h f r-t s^{+-}$mutant infected mice. Taken together, protection and T-cell studies indicate that resistance to reinfection is long lasting and is sustained by immune cells probably responding to a set of epitopes broader than TSKb20.

\section{Final Conclusions}

Gene targeted deletion through homologous recombination has been one of the most important tools developed for the study of gene functions, especially for those organisms in which gene silencing via interference RNA is not possible. Targeted deletion of specific genes can also be regarded as a potential procedure to generate clones of pathogenic organisms capable of growing in vitro but less efficient to invade and persist in vivo. Therefore, this strategy provides the potential for mass production of attenuated pathogens with a built-in safety device against reversion to virulent phenotypes.

The first $T$. cruzi mutant strain lacking a complete functional gene was developed about 17 y ago. ${ }^{18}$ Despite this considerable passage of time, only a few $T$. cruzi strains carrying specific gene deletions have been developed. ${ }^{712-25}$ It seems that $T$. cruzi is an organism where gene-targeted deletion and gene silencing have so far not been applied as productively as in other trypanosomatids, such as Trypanosoma brucei and Leishmania. However, the few studies in which T. cruzi mutants were compared with wild-type parasites using infectivity measurements almost invariably revealed a change toward attenuation of virulence.

The use of $T$. cruzi attenuated parasites is appealing since the infection induced is limited and may consequently lead to the establishment of a protective immune response. However, genome manipulation could lead to a loss of the protective immunity either because such genetically modified parasites cannot survive long enough to fully activate the immune system or, because they do not express antigen epitopes essential for triggering a good immune response, albeit less likely. For these reasons, a wide spectrum of specific individual genes or a combination of them (as well as different $T$. cruzi strains) should be evaluated.

In summary, genetically modified live parasites may be better and safer inducers of a protective immune response than non-replicating immunogens. They might be applicable to dogs and other mammals that act as natural reservoirs with the potential for reducing the intensity 


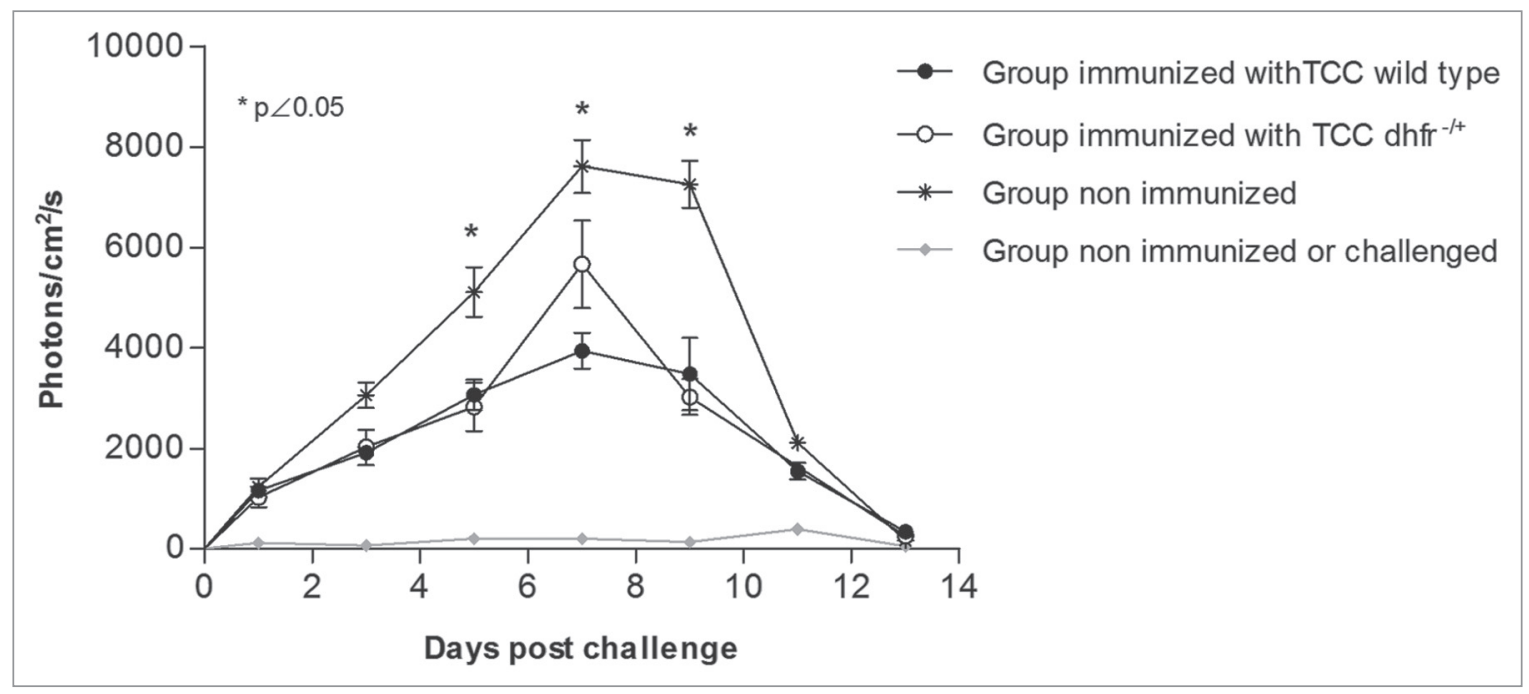

Figure 2. Long-term protective immunization with TCC $d h f r-t s^{+/}$metacyclic trypomastigotes against virulent challenge with fluorescent $T$. cruzi parasites. Parasite load after challenge, at day 370 post infection, with $2.5 \times 10^{5}$ bloodstream forms of the virulent CL-tdTomato strain. ${ }^{42}$ Fluorescence levels were measured during $13 \mathrm{~d}$. Values are given as means; error bars indicate standard errors of the means (e1418. doi:10.1371/journal.pntd.0001418. g006).

and spread of the disease. Therefore, this work sets a precedent, not only for the development of new improved molecular techniques for gene deletion but for the generation of genetically attenuated parasites which could be safely used as a potential vaccine against Chagas disease.

\section{Acknowledgements}

We would like to thank all the researchers and technicians of the Instituto de Patologia Experimental for their continuous efforts to investigate the biology of $T$. cruzi. We are grateful to Dr. Luis Parada for critical revising the manuscript and to Dr. Rick Tarleton for his helpful discussions and contributions during this study.

\section{References}

1. WHO/TDR. Epidemiology of Chagas' disease, past and present. Report of the Scientific Working Group on Chagas' disease 2007.

2. Fitchett JR, Cooke MK. Genetically engineered parasites: the solution to designing an effective malaria vaccine? Trends Parasitol 2010; 26:3223; PMID:20537954; http://dx.doi.org/10.1016/j. pt.2010.04.008.

3. Vaughan AM, Wang R, Kappe SH. Genetically engineered, attenuated whole-cell vaccine approaches for malaria. Hum Vaccin 2010; 6:10713; PMID:19838068; http://dx.doi.org/10.4161/ hv.6.1.9654.

4. Silvestre R, Cordeiro-da-Silva A, Ouaissi A. Live attenuated Leishmania vaccines: a potential strategic alternative. Arch Immunol Ther Exp (Warsz) 2008; 56:123-6; PMID:18373245; http://dx.doi. org/10.1007/s00005-008-0010-9.
5. Barrio AB, Van Voorhis WC, Basombrío MA Trypanosoma cruzi: attenuation of virulence and protective immunogenicity after monoallelic disruption of the cub gene. Exp Parasitol 2007; 117:382-9; PMID:17624327; http://dx.doi.org/10.1016/j.exppara.2007.05.005.

6. Collins MH, Craft JM, Bustamante JM, Tarleton RL. Oral exposure to Trypanosoma cruzi elicits a systemic CD8 ${ }^{+} \mathrm{T}$ cell response and protection against heterotopic challenge. Infect Immun 2011; 79:3397406; PMID:21628516; http://dx.doi.org/10.1128/ IAI.01080-10.

7. Perez Brandan C, Padilla AM, Xu D, Tarleton RL, Basombrio MA. Knockout of the dhfr-ts gene in Trypanosoma cruzi generates attenuated parasites able to confer protection against a virulent challenge. PLoS Negl Trop Dis 2011; 5:1418; PMID:22180798; http://dx.doi.org/10.1371/journal.pntd.0001418

8. Zago MP, Barrio AB, Cardozo RM, Duffy $T$, Schijman AG, Basombrío MA. Impairment of infectivity and immunoprotective effect of a LYT1 null mutant of Trypanosoma cruzi. Infect Immun 2008; 76:443-51; PMID:17938222; http://dx.doi. org/10.1128/IAI.00400-07.

9. Gómez ND, Safeukui I, Adelani AA, Tewari R, Reddy JK, Rao S, et al. Deletion of a malaria invasion gene reduces death and anemia, in model hosts. PLoS One 2011; 6:25477; PMID:21980474; http://dx.doi. org/10.1371/journal.pone.0025477.

10. Manthri S, Güther ML, Izquierdo L, Acosta-Serrano A, Ferguson MA. Deletion of the TbALG3 gene demonstrates site-specific $\mathrm{N}$-glycosylation and $\mathrm{N}$-glycan processing in Trypanosoma brucei. Glycobiology 2008; 18:367-83; PMID:18263655; http://dx.doi. org/10.1093/glycob/cwn014.

11. Munday JC, McLuskey K, Brown E, Coombs GH, Mottram JC. Oligopeptidase B deficient mutants of Leishmania major. Mol Biochem Parasitol 2011; 175:49-57; PMID:20883728; http://dx.doi. org/10.1016/j.molbiopara.2010.09.003.

12. Ajioka J, Swindle J. The calmodulin-ubiquitin (CUB) genes of Trypanosoma cruzi are essential for parasite viability. Mol Biochem Parasitol 1996; 78:217-25; PMID:8813691; http://dx.doi.org/10.1016/S01666851(96)02627-8.
13. Allaoui A, François C, Zemzoumi K, Guilvard E, Ouaissi A. Intracellular growth and metacyclogenesis defects in Trypanosoma cruzi carrying a targeted deletion of a Tc52 protein-encoding allele. Mol Microbio 1999; 32:1273-86; PMID:10383767; http://dx.doi. org/10.1046/j.1365-2958.1999.01440.x.

14. Annoura T, Nara T, Makiuchi T, Hashimoto T, Aoki T. The origin of dihydroorotate dehydrogenase genes of kinetoplastids, with special reference to their biological significance and adaptation to anaerobic, parasitic conditions. J Mol Evol 2005; 60:11327; PMID:15696374; http://dx.doi.org/10.1007/ s00239-004-0078-8.

15. Caler EV, Vaena de Avalos S, Haynes PA, Andrews NW, Burleigh BA. Oligopeptidase B-dependent signaling mediates host cell invasion by Trypanosoma cruzi. EMBO J 1998; 17:4975-86; PMID:9724634; http://dx.doi.org/10.1093/emboj/17.17.4975.

16. Campos PC, Silva VG, Furtado C, Machado-Silva A, Darocha WD, Peloso EF, et al. Trypanosoma cruzi MSH2: Functional analyses on different parasite strains provide evidences for a role on the oxidative stress response. Mol Biochem Parasitol 2011; 176:816; PMID:21073906; http://dx.doi.org/10.1016/j. molbiopara.2010.11.001.

17. Conte I, Labriola C, Cazzulo JJ, Docampo R, Parodi AJ. The interplay between folding-facilitating mechanisms in Trypanosoma cruzi endoplasmic reticulum. Mol Biol Cell 2003; 14:3529-40; PMID:12972544; http://dx.doi.org/10.1091/mbc.E03-04-0228.

18. Cooper R, de Jesus AR, Cross GA. Deletion of an immunodominant Trypanosoma cruzi surface glycoprotein disrupts flagellum-cell adhesion. J Cell Biol 1993; 122:149-56; PMID:8314840; http://dx.doi. org/10.1083/jcb.122.1.149.

19. de Souza FS, Rampazzo Rde C, Manhaes L, Soares MJ, Cavalcanti DP, Krieger MA, et al. Knockout of the gene encoding the kinetoplast-associated protein 3 (KAP3) in Trypanosoma cruzi: effect on kinetoplast organization, cell proliferation and differentiation. Mol Biochem Parasitol 2010; 172:90-8; PMID:20363262; http://dx.doi.org/10.1016/j.molbiopara.2010.03.014. 
20. Gluenz E, Taylor MC, Kelly JM. The Trypanosoma cruzi metacyclic-specific protein Met-III associates with the nucleolus and contains independent amino and carboxyl terminal targeting elements. Int J Parasitol 2007; 37:617-25; PMID:17239886; http:// dx.doi.org/10.1016/j.ijpara.2006.11.016.

21. MacRae JI, Obado SO, Turnock DC, Roper JR, Kierans M, Kelly JM, et al. The suppression of galactose metabolism in Trypanosoma cruzi epimastigotes causes changes in cell surface molecular architecture and cell morphology. Mol Biochem Parasitol 2006; 147:126-36; PMID:16569451; http://dx.doi. org/10.1016/j.molbiopara.2006.02.011.

22. Manning-Cela R, Cortés A, González-Rey E, Van Voorhis WC, Swindle J, González A. LYT1 protein is required for efficient in vitro infection by Trypanosoma cruzi. Infect Immun 2001; 69:391623; PMID:11349059; http://dx.doi.org/10.1128/ IAI.69.6.3916-23.2001.

23. Serpeloni M, Moraes CB, Muniz JR, Motta MC, Ramos AS, Kessler RL, et al. An essential nuclear protein in trypanosomes is a component of mRNA transcription/export pathway. PLoS One 2011; 6:20730 PMID:21687672; http://dx.doi.org/10.1371/journal. pone. 0020730 .

24. Wilkinson SR, Taylor MC, Horn D, Kelly JM, Cheeseman I. A mechanism for cross-resistance to nifurtimox and benznidazole in trypanosomes. Proc Natl Acad Sci USA 2008; 105:50227; PMID:18367671; http://dx.doi.org/10.1073/ pnas. 0711014105

25. Xu D, Brandán CP, Basombrío MA, Tarleton RL. Evaluation of high efficiency gene knockout strategies for Trypanosoma cruzi. BMC Microbiol 2009; 9:90; PMID:19432966; http://dx.doi.org/10.1186/14712180-9-90.

26. Ivanetich KM, Santi DV. Bifunctional thymidylate synthase-dihydrofolate reductase in protozoa. FASEB J 1990; 4:1591-7; PMID:2180768.
27. Cruz A, Coburn CM, Beverley SM. Double targeted gene replacement for creating null mutants. Proc Nat Acad Sci USA 1991; 88:7170-4; PMID:1651496; http://dx.doi.org/10.1073/pnas.88.16.7170.

28. Sienkiewicz N, Jarosławski S, Wyllie S, Fairlamb AH. Chemical and genetic validation of dihydrofolate reductase-thymidylate synthase as a drug target in African trypanosomes. Mol Microbiol 2008; 69:520 33; PMID:18557814; http://dx.doi.org/10.1111/ j.1365-2958.2008.06305.x.

29. Cruz AK, Titus R, Beverley SM. Plasticity in chromosome number and testing of essential genes in Leishmania by targeting. Proc Natl Acad Sci USA 1993; 90:1599-603; PMID:8381972; http://dx.doi org/10.1073/pnas.90.4.1599.

30. Mukherjee A, Langston LD, Ouellette $M$. Intrachromosomal tandem duplication and repeat expansion during attempts to inactivate the subtelomeric essential gene GSH1 in Leishmania. Nucleic Acids Res 2011; 39:7499-511; PMID:21693561; http://dx.doi.org/10.1093/nar/gkr494.

31. Titus RG, Gueiros-Filho FJ, de Freitas LA, Beverley SM. Development of a safe live Leishmania vaccine line by gene replacement. Proc Natl Acad Sci USA 1995; 92:10267-71; PMID:7479765; http://dx.doi. org/10.1073/pnas.92.22.10267.

32. Bustamante JM, Bixby LM, Tarleton RL. Druginduced cure drives conversion to a stable and protective $\mathrm{CD}^{+} \mathrm{T}$ central memory response in chronic Chagas disease. Nat Med 2008; 14:542 50; PMID:18425131; http://dx.doi.org/10.1038/ nm1744.

33. CDC, Ed. Epidemiology and Prevention of VaccinePreventable Diseases. Atlanta, Georgia 2012.

34. Dhillon S, Curran MP. Live attenuated measles, mumps, rubella and varicella zoster virus vaccine (Priorix-Tetra). Paediatr Drugs 2008, 10:337-47; PMID:18754700; http://dx.doi. org/10.2165/00148581-200810050-00007.
35. McShane H. Tuberculosis vaccines: beyond bacille Calmette-Guerin. Philos Trans R Soc Lond B Biol Sci 2011; 366:2782-9; PMID:21893541; http://dx.doi. org/10.1098/rstb.2011.0097.

36. Miller JD, van der Most RG, Akondy RS, Glidewell JT, Albott S, Masopust D, et al. Human effector and memory $\mathrm{CD}^{+} \mathrm{T}$ cell responses to smallpox and yellow fever vaccines. Immunity $2008 ; 28: 710$ 22; PMID:18468462; http://dx.doi.org/10.1016/j. immuni.2008.02.020.

37. Padilla AM, Bustamante JM, Tarleton RL. CD8 $\mathrm{T}$ cells in Trypanosoma cruzi infection. Curr Opin Immunol 2009; 21:385-90; PMID:19646853; http://dx.doi.org/10.1016/j.coi.2009.07.006.

38. Martin DL, Weatherly DB, Laucella SA, Cabinian MA, Crim MT, Sullivan S, et al. CD8 ${ }^{+}$T-Cel responses to Trypanosoma cruzi are highly focused on strain-variant trans-sialidase epitopes. PLoS Pathog 2006; 2:77; PMID:16879036; http://dx.doi. org/10.1371/journal.ppat.0020077.

39. Basombrío MA, Besuschio S. Trypanosoma cruzi culture used as vaccine to prevent chronic Chagas disease in mice. Infect Immun 1982; 36:351-6, PMID:6804390

40. Basombrío MA, Arredes H, Uncos DA, Rossi R, Alvarez E. Field trial of vaccination against American trypanosomiasis (Chagas' disease) in domestic guin ea pigs. Am J Trop Med Hyg 1987; 37:57-62 PMID:3111281

41. Basombrio MA, Segura MA, Mora MC, Gomez L. Field trial of vaccination against American trypanosomiasis (Chagas' disease) in dogs. Am J Trop Med Hyg 1993; 49:143-51; PMID:8352387.

42. Canavaci AM, Bustamante JM, Padilla AM, Perez Brandan CM, Simpson LJ, Xu D, et al. In vitro and in vivo high-throughput assays for the testing of anti-Trypanosoma cruzi compounds. PLoS Negl Trop Dis 2010; 4:740; PMID:20644616; http://dx.doi. org/10.1371/journal.pntd.0000740. 